\title{
Surface microhardness of a self-adhesive composite in comparison with conventional composite resins
}

\section{Mikrotwardość powierzchni samoadhezyjnego materiału kompozytowego w porównaniu z klasycznymi żywicami kompozytowymi}

\author{
Sedighe Sadat Hashemikamangar ${ }^{1, A, E, F}$, Mohammad Zeynaddini Meymand ${ }^{2, B, D}$, Mohammad Javad Kharazifard ${ }^{3, C}$, Sara Valizadeh ${ }^{1, A, E, F}$ \\ 1 Department of Operative Dentistry, School of Dentistry, Tehran University of Medical Sciences, Iran \\ ${ }^{2}$ Department of Periodontology, Dental School, Mashhad University of Medical Sciences, Iran \\ ${ }^{3}$ Dental Research Center, Dentistry Research Institute, Tehran University of Medical Sciences, Iran \\ A - research concept and design; $\mathrm{B}$ - collection and/or assembly of data; $\mathrm{C}$ - data analysis and interpretation; \\ $D$ - writing the article; $E$ - critical revision of the article; $F$ - final approval of the article
}

Address for correspondence

Sara Valizadeh

E-mail: valizadeh_s@sina.tums.ac.ir

Funding sources

None declared

Conflict of interest

None declared

Acknowledgements

This article was part of a MD thesis, supported by Tehran University of Medical Sciences in Iran (grant No. 97-01-70-37806).

Received on August 22, 2019

Reviewed on November 24, 2019

Accepted on February 10, 2020

Published online on September 30, 2020

Cite as

Hashemikamangar SS, Meymand MZ, Kharazifard MJ,

Valizadeh S. Surface microhardness of a self-adhesive composite in comparison with conventional composite resins. Dent Med Probl. 2020;57(3):247-253. doi:10.17219/dmp/118123

DOI

$10.17219 / \mathrm{dmp} / 118123$

Copyright

( 2020 by Wroclaw Medical University

This is an article distributed under the terms of the

Creative Commons Attribution 3.0 Unported License (CC BY 3.0)

(https://creativecommons.org/licenses/by/3.0/).

\begin{abstract}
Background. The surface microhardness of dental composites greatly affects the durability of restorations.

Objectives. The aim of this study was to compare the surface microhardness of a self-adhesive composite with that of other conventional composites. The effect aging has on surface microhardness was also evaluated.
\end{abstract}

Material and methods. In this in vitro experimental study, the composite resins were poured into molds measuring $3 \mathrm{~mm} \times 3 \mathrm{~mm} \times 6 \mathrm{~mm}$ and cured for 40 s. The samples were then immersed in distilled water at $37^{\circ} \mathrm{C}$ for $24 \mathrm{~h}$. After polishing, the surface microhardness of the samples was measured using the Vickers hardness tester. For this purpose, a 100-gram load was applied to 3 points on the surface of each composite sample for $20 \mathrm{~s}$, and the mean value of surface microhardness was used as the Vickers hardness number. The samples were then subjected to 30,000 thermal cycles at $5-55^{\circ} \mathrm{C}$ in order to age them; after that, their surface microhardness was measured again. The one-way analysis of variance (ANOVA) was used for the statistical analysis.

Results. The maximum hardness value before and after aging belonged to Filtek ${ }^{\circledR} Z 250$, followed by Premise ${ }^{\mathrm{TM}}$ Flow and Vertise ${ }^{\mathrm{TM}}$ Flow, with significant differences between them $(p<0.001)$. After aging, the surface microhardness of all composites decreased significantly $(p<0.001)$. The effect of aging on surface microhardness was the same in all groups $(p>0.05)$.

Conclusions. The surface microhardness of composites was significantly different before and after aging. All composites experienced a reduction in their surface microhardness after aging.

Key words: aging, self-adhesive composite, surface microhardness

Słowa kluczowe: starzenie się, samoadhezyjny materiał kompozytowy, mikrotwardość powierzchni 


\section{Introduction}

Dental composites have grown in popularity due to their optimal esthetics, favorable physical and mechanical properties, easy application, and ability to bond to the tooth structures. ${ }^{1}$

Optimal durability is the main prerequisite for successful composite restorations; it depends on the inherent properties of the material as well as on its surrounding environment. In recent decades, great strides have been made in restoring the function and morphology of the lost tooth structure with the use of composite resins. ${ }^{2}$ The preparation of the enamel and the dentin surface is time-consuming and constitutes one of the challenges encountered in restoring the teeth with composites. Thus, researchers have always been in search of methods that would reduce the clinical steps in order to minimize the risk of contamination and the subsequent failure of composite restorations. Such failure may include marginal discoloration, secondary caries and the debonding of the restoration from the tooth structure. ${ }^{3}$ Recently, a new type of flowable composites - self-adhesive composites - have been introduced onto the market. The manufacturers claim that self-adhesive composites eliminate the need for a separate bonding step, and thereby reduce the clinical working time and enhance the process of tooth restoration. ${ }^{4}$ Vertise ${ }^{\mathrm{TM}}$ Flow by Kerr is one of self-adhesive composite resins. The manufacturer claims that it is ideal for small class I and class II restorations, fissure sealant therapy and porcelain repair. ${ }^{5}$

The prognosis and clinical service of restorations depend on the physical, mechanical and biological properties of the material used. Surface microhardness is an important physical property, assessed in order to determine the durability of restorations. The surface microhardness of restorative materials may be diminished due to the continuous contact with saliva and the application of masticatory forces and stresses. ${ }^{6}$ Surface microhardness depends on the cohesive strength of the material and on the presence of wear caused to or by the opposing teeth. Hardness refers to the resistance of the material against indentation and is an important criterion with regard to the shape and durability of restorations over time. The higher the filler content and the degree of polymerization of composite resins, the higher their surface hardness is. The smooth, hard surfaces of restorations create esthetic appearance as well as decrease the accumulation of plaque. Worn, abraded surfaces cause plaque to accumulate and increase the risk of caries development around the margins of restorations. Optimal hardness is required to maintain the form and stability of composite restorations against flexural stresses from complex chewing forces in the oral environment. ${ }^{7}$

A clinical setting is often simulated by artificial aging in order to assess the effect of saliva and masticatory forces in vitro, since clinical tests are costly and time- consuming. The mechanical characteristics of dental composite materials, like Vickers hardness, could be influenced by artificial aging. Thermocycling and water storage are among the well-known and accepted techniques for aging. ${ }^{8}$ Thermocycling is often done to age dental composite resins. In this technique, samples are subjected to frequent thermal alterations. High temperatures decrease the physical and chemical properties of composite resins. Thermal alterations can reduce the number of unreacted double bonds on the surface of or within the composite resin. ${ }^{9}$

The water absorption of the resin matrix and the hydrolysis of the filler-matrix interface can cause the composite restoration to deteriorate. Leachates from the composite restoration in the oral cavity might disturb the mechanical and physical properties of the polymers. A decrease in the integrity of the resin composite may contribute to its longevity being compromised.

Thus, considering the significance of the surface hardness of composites, the introduction of self-adhesive composites and the gap in information regarding the effect aging has on the surface microhardness of selfadhesive composites, this study was designed to assess the effect of aging on the surface microhardness of a selfadhesive composite in comparison with conventional composites.

\section{Material and methods}

This in vitro experimental study evaluated a methacrylate-based microhybrid composite (A2 shade of Filtek ${ }^{\circledR}$ Z250; 3M ESPE, St. Paul, USA), a nanofill composite (A2 shade of Premise ${ }^{\text {тм }}$ Flow; Kerr, Bolzano, Italy), and a selfadhesive composite resin (A2 shade of Vertise Flow; Kerr) $(n=14)$. Table 1 presents the characteristics of the materials used in this study.

The composite resins were poured into plexiglass molds measuring $3 \mathrm{~mm} \times 3 \mathrm{~mm} \times 6 \mathrm{~mm}$. The mold was placed on a glass slab measuring $3 \mathrm{~mm} \times 3 \mathrm{~mm} \times 6 \mathrm{~mm}$ and the composite was applied to the mold. Another glass slab was placed over it and a 5-kilogram weight was used to apply pressure from the top for $3 \mathrm{~min}$. This was done to ensure uniform thickness of the samples and to eliminate any voids. The samples were then light-cured from each side for $20 \mathrm{~s}$ using an LED light-curing unit (Guilin Woodpecker Medical Instrument Co., Ltd., Guilin, China) with a light intensity of $1,000 \mathrm{~mW} / \mathrm{cm}^{2}$. Light intensity was checked after every 5 samples by using a radiometer (Optilux ${ }^{\circledR} 100$; Demetron/Kerr, Danbury, USA). After curing, the samples were immersed in distilled water at $37^{\circ} \mathrm{C}$ for $24 \mathrm{~h}$. The upper surfaces of the samples were polished using 1,000- and 2,000-grit silicon carbide abrasive papers in order to obtain smooth surfaces with no contamination. Polishing was done under gentle water irrigation for $20 \mathrm{~s}$. 
Table 1. Characteristics of the materials used in the study

\begin{tabular}{|c|c|c|}
\hline Material & Composition & Manufacturer \\
\hline $\begin{array}{l}\text { Filtek } \\
\text { Z250 }\end{array}$ & $\begin{array}{l}\text { filler: } \\
0.01-3.5 \mu \mathrm{m} \mathrm{Zr} / \mathrm{Si} \text { ( } 60 \% \text { by volume) } \\
\text { resin: } \\
\text { - Bis-GMA } \\
\text { - Bis-EMA } \\
\text { - UDMA }\end{array}$ & $\begin{array}{c}\text { 3M ESPE, } \\
\text { St. Paul, USA }\end{array}$ \\
\hline $\begin{array}{l}\text { Premise } \\
\text { Flow }\end{array}$ & $\begin{array}{l}\text { filler: } \\
-0.4 \mu \mathrm{m} \text { barium glass ( } 75.5 \% \text { by weight) } \\
-30-50 \mu \mathrm{m} \text { pre-polymerized fillers } \\
-0.02 \mu \mathrm{m} \text { silica nanoparticles } \\
\text { resin: } \\
\text { - Bis-GMA } \\
\text { - Bis-EMA } \\
\text { - TEGDMA } \\
\text { - light-cure initiators and stabilizers }\end{array}$ & $\begin{array}{c}\text { Kerr, } \\
\text { Bolzano, Italy }\end{array}$ \\
\hline $\begin{array}{l}\text { Vertise } \\
\text { Flow }\end{array}$ & $\begin{array}{l}\text { filler: } \\
\text { - pre-polymerized fillers containing } 0.7 \mu \mathrm{m} \text { Ba } \\
\text { - } 1 \mu \mathrm{m} \text { barium glass } \\
\text { - } 10-40 \mathrm{~nm} \text { nanosized colloidal silica } \\
\text { - } 40 \mathrm{~nm} \text { nanosized YbF3 } \\
\text { resin: } \\
\text { - Bis-GMA } \\
\text { - Bis-EMA } \\
\text { - BISPAD, } \\
\text { - GDMA adhesive monomer, incorporating } \\
\text { Kerr OptiBond }{ }^{\mathrm{TM}} \text { adhesion technology }\end{array}$ & $\begin{array}{c}\text { Kerr, } \\
\text { Bolzano, Italy }\end{array}$ \\
\hline
\end{tabular}

Bis-GMA - bisphenol A-glycidyl methacrylate; Bis-EMA - ethoxylated bisphenol A-glycidyl methacrylate; UDMA - urethane

dimethacrylate; TEGDMA - triethylene glycol dimethacrylate; BISPAD - (1S,2S)-1-phenyl-2-amino-1,3-propanediol bis-silylate: GPDM - glycero-phosphate dimethacrylate.

\section{Vickers hardness test}

The Vickers hardness test (in micron scale) was performed on the composite samples using a Vickers hardness tester (MH3 model; Koopa Pazhoohesh, Tehran, Iran). For this purpose, a 200-gram load was applied to 3 points on the surface of the sample for $15 \mathrm{~s}$; the mean value of surface microhardness was calculated and used as the hardness number of the sample.

\section{Aging}

The samples were thermocycled to simulate aging $-30,000$ cycles at $5-55^{\circ} \mathrm{C}$ with a dwell time of $20 \mathrm{~s}$ and a transfer time of $10 \mathrm{~s}$. Then, they were again subjected to the hardness test.

\section{Statistical analysis}

The two-way repeated measurement analysis of variance (ANOVA) with a significance level of 0.05 was performed to compare the microhardness of different composite samples before and after aging by considering their microhardness at different time points as the repeated factor, and aging and the type of composite as betweensubject factors. The data was analyzed with PASW Statistics for Windows v. 18 (SPSS, Inc., Chicago, USA).

\section{Scanning electron microscopy}

Two additional samples were fabricated in each group for scanning electron microscopy (SEM) assessment. The samples were dried and coated with gold. The surfaces of the samples were inspected under an electron microscope (TESCAN VEGA, Brno, Czech Republic) at $\times 3,000$ magnification and a voltage of $20 \mathrm{kV}$ before and after aging.

\section{Results}

Table 2 shows the means $(M)$ and standard deviations $(S D)$ of the Vickers hardness number for the 3 types of composites before and after aging. Before aging, the highest hardness number belonged to Filtek Z250 $\left(100.09 \pm 3.32 \mathrm{~N} / \mathrm{mm}^{2}\right)$, followed by Premise Flow $\left(49.10 \pm 2.26 \mathrm{~N} / \mathrm{mm}^{2}\right)$ and Vertise Flow $\left(43.19 \pm 1.53 \mathrm{~N} / \mathrm{mm}^{2}\right)$. The differences between the groups in this regard were significant $(p<0.001)$.

The surface microhardness of all composites significantly decreased after aging $(p<0.001)$. The effect of aging on microhardness was the same in all groups and no significant differences were noted between the different composites in the degree to which their surface microhardness was diminished after aging $(p=0.058)$.

After aging, the highest microhardness value was noted in the Filtek Z250 group ( $\left.85.47 \pm 5.01 \mathrm{~N} / \mathrm{mm}^{2}\right)$, followed by Premise Flow $\left(38.13 \pm 1.58 \mathrm{~N} / \mathrm{mm}^{2}\right)$ and Vertise Flow $\left(31.87 \pm 1.44 \mathrm{~N} / \mathrm{mm}^{2}\right)$. The differences between the groups in this regard were significant $(p<0.001)$.

Figures 1-6 show SEM images for the different types of composite used in this study before and after aging. Also, the mean values with $S D$ s of the microhardness of the 3 composites are presented in Fig. 7 .

Table 2. Surface microhardness [N/mm²] of the composites before and after aging $(n=14)$

\begin{tabular}{|c|c|c|c|c|c|c|}
\hline Composite & Time point & Minimum value & Maximum value & $M$ & $S D$ & $p$-value \\
\hline \multirow{2}{*}{ Filtek Z250 } & before aging & 95.77 & 106.00 & 100.09 & 3.32 & $0.001^{\mathrm{a}}$ \\
\hline & after aging & 77.97 & 95.03 & 85.47 & 5.01 & $0.001^{d}$ \\
\hline \multirow{2}{*}{ Premise Flow } & before aging & 44.87 & 54.73 & 49.10 & 2.26 & $0.001^{b}$ \\
\hline & after aging & 34.83 & 40.07 & 38.13 & 1.58 & $0.001^{e}$ \\
\hline \multirow{2}{*}{ Vertise Flow } & before aging & 40.50 & 45.23 & 43.19 & 1.53 & $0.001^{c}$ \\
\hline & after aging & 29.43 & 34.40 & 31.87 & 1.44 & $0.001^{f}$ \\
\hline
\end{tabular}

$M$ - mean; SD - standard deviation. Different superscript letters show significant differences. 


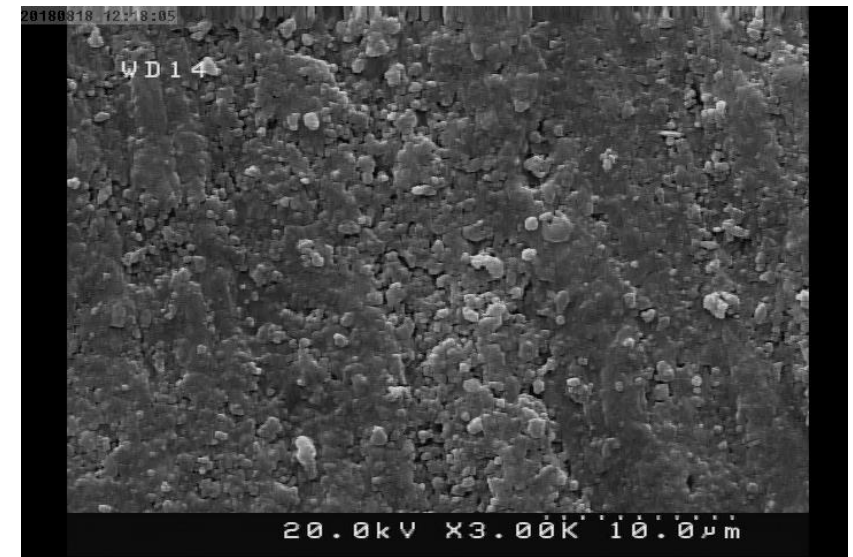

Fig. 1. Filtek Z250 before aging

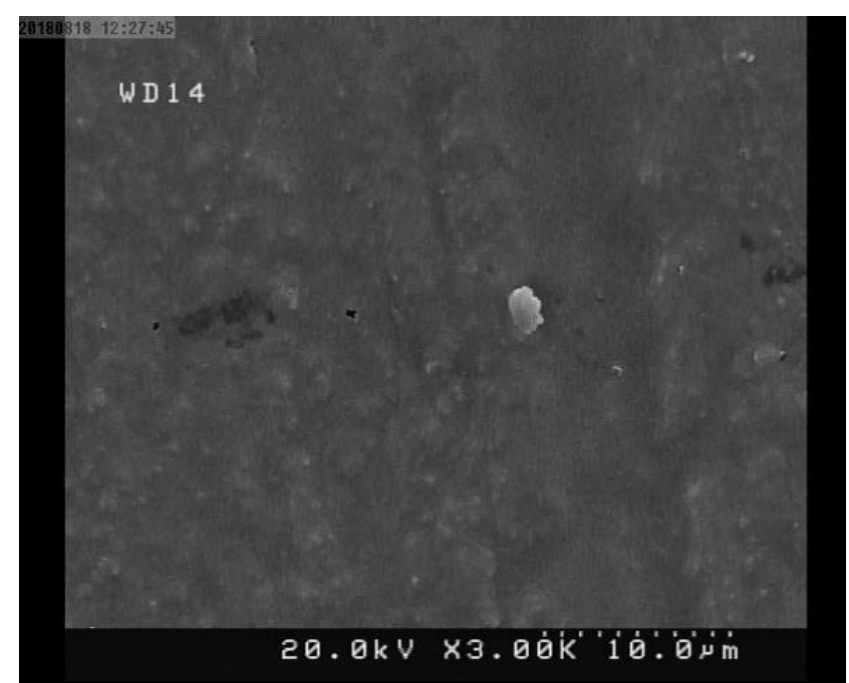

Fig. 2. Filtek Z250 after aging

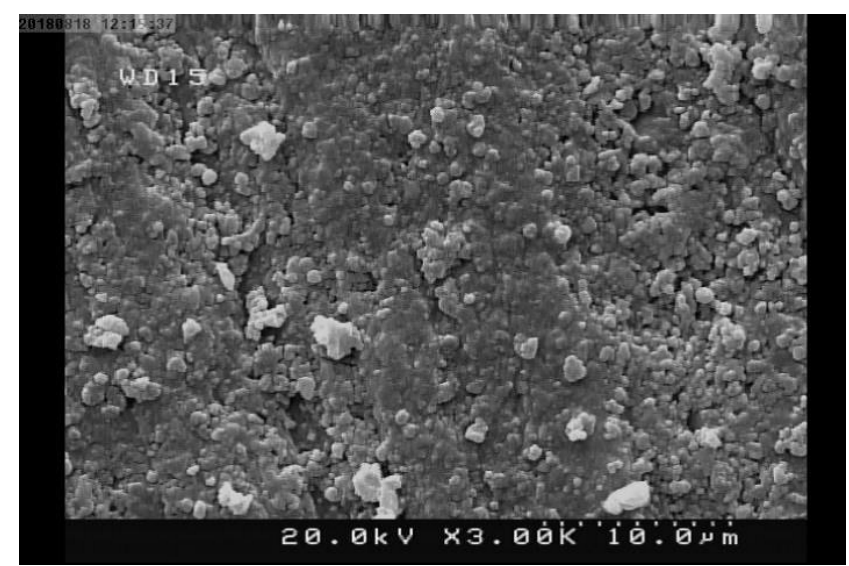

Fig. 3. Premise Flow before aging

\section{Discussion}

There are several laboratory tests which assess the mechanical stability of materials, including the tests of flexural strength, tensile strength, compressive strength, fracture toughness, surface microhardness, and the modulus of elasticity. ${ }^{10}$

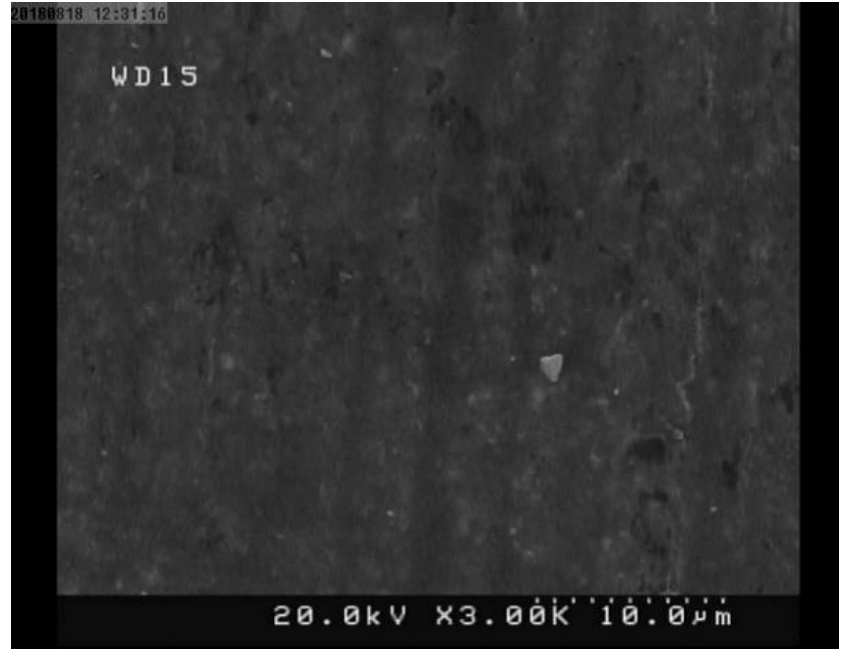

Fig. 4. Premise Flow after aging

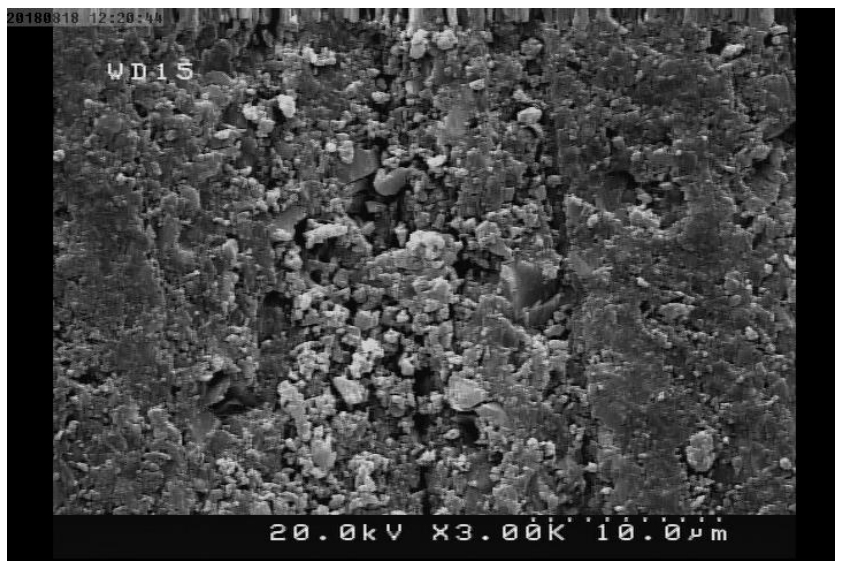

Fig. 5. Vertise Flow before aging

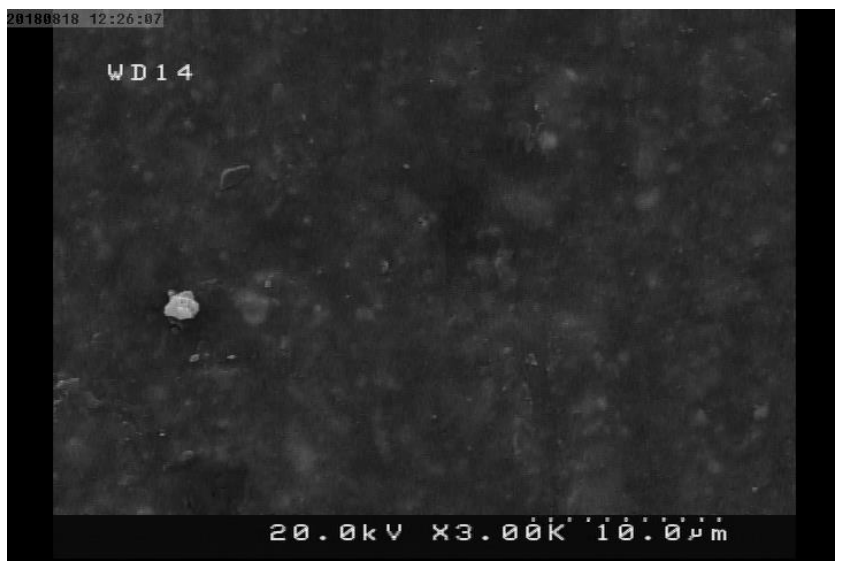

Fig. 6. Vertise Flow after aging

The present in vitro study assessed the surface microhardness of a self-adhesive flowable composite, a microhybrid composite and a nanofill composite before and after aging. The knowledge of the mechanical properties of composite resins is imperative in order to understand and predict their clinical behavior and longevity. ${ }^{11}$ This study revealed significant differences in the surface 


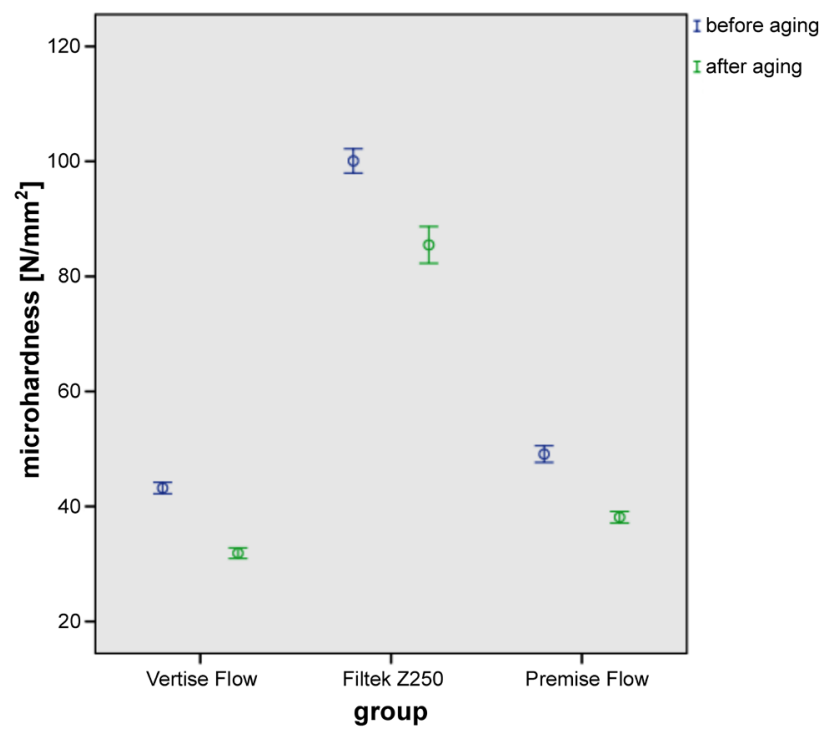

Fig. 7. Mean (M) and standard deviation (SD) values of microhardness for the 3 composites before and after aging

microhardness of the composites before and after aging. The surface microhardness of all composites was significantly different among them before and after aging. Before aging, Filtek Z250 showed the highest microhardness, followed by Premise Flow and Vertise Flow. The composites were in the same order of microhardness after aging.

The results suggest that surface microhardness highly depends on the type of material and is affected by the quality of the fillers (the percentage of fillers by weight and volume as well as their size, shape and distribution) and of the matrix. Also, it has been reported that the degree of conversion of composites is positively correlated with their surface microhardness. ${ }^{12}$

In this study, Filtek Z250 had the highest volume percentage of the fillers (60\%), followed by Premise Flow (60\%) and Vertise Flow (44\%). According to ScougallVilchis et al., surface microhardness depends on the size and volume and weight percentage of the fillers as well as on the chemical composition of the composite resin. ${ }^{13}$ As the volume percentage of the fillers increases, the flexural strength, modulus of elasticity and surface microhardness of the composite also increase. ${ }^{13}$ However, this statement does not apply to all materials, because Premise Flow showed lower microhardness values than Filtek Z250, although they share an almost equal weight and volume percentage of the fillers.

The type of fillers may be one explanation of the higher microhardness of Filtek Z250, since its fillers mainly include crystalline silica and zirconia, which are harder than the amorphous glasses in the composition of the other 2 composites. ${ }^{14}$ Craig suggested that composites with harder filler particles demonstrate a higher surface microhardness as well. acc.15 Moreover, the composites with pre-polymerized fillers showed significantly lesser microhardness in our study. Blackham et al. reported that composite resins containing pre-polymerized fillers behaved more poorly in the hardness and strength tests than conventional hybrid composites such as Filtek Z250. ${ }^{16}$ Pre-polymerized fillers are added to composite resins primarily to minimize their dimensional changes during polymerization and to decrease the amount of unpolymerized resin. However, the addition of pre-polymerized resin may lead to poorer mechanical properties. ${ }^{17}$ Moreover, differences in the distribution and size of the fillers can cause differences in the hardness of the composites containing this type of filler. ${ }^{18}$

The composition of the organic matrix is another factor that affects the surface microhardness of composite resins. The organic matrix of Filtek Z250 includes bisphenol A-glycidyl methacrylate (Bis-GMA), ethoxylated bisphenol A-glycidyl methacrylate (Bis-EMA) and urethane dimethacrylate (UDMA). The organic matrix of Vertise Flow, however, contains Bis-GMA, Bis-EMA, (1S,2S)-1-phenyl-2-amino-1,3-propanediol bis-silylate (BISPAD), and glycero-phosphate dimethacrylate (GPDM). Different monomers have different properties. They may vary in their degree of hydrophilicity, degree of conversion or cross-linking during polymerization. ${ }^{19}$ Filtek Z250 does not contain the TEGDMA monomer in its composition. It is a low-molecular-weight monomer whereas UDMA and Bis-EMA have higher molecular weights. All of these monomers are added as thinners, along with Bis-GMA. Moreover, Filtek Z250 contains UDMA, which is much more reactive than other monomers. ${ }^{20}$ Urethane dimethacrylate has a very flexible structure with weak hydrogen bonds, probably due to the presence of a urethane group in its structure. This explains the higher degree of conversion of this monomer, and the degree of conversion directly affects hardness. ${ }^{21}$

Filtek Z250 may contain higher amounts of photoinitiators than other composite resins, which may be another explanation for its higher Vickers hardness number. Manufacturers do not often disclose the amount of photoinitiators in the composition of composite resins. However, according to David et al., 3 types of photoinitiators - camphorquinone (CQ), tertiary amine, and iodonium salt - are present in the composition of the 3M ESPE composite resins. ${ }^{22}$ Iodonium salt may play an important role in increasing the polymerization rate of composite resins. ${ }^{22}$

In the present study, the hardness of all composites significantly worsened after 30,000 thermal cycles, which corresponds to 3 years of clinical service. ${ }^{23}$ There is no consensus regarding the effect of thermocycling on the mechanical properties of composite resins, such as surface microhardness. De Moraes et al. found that the modulus of elasticity and hardness of composite resins decreased after 6 months of water storage. ${ }^{24}$ Conversely, Yap et al. reported no change in the modulus of elasticity or hardness of the composite resins stored in water for 30 days. ${ }^{25}$ Hahnel et al. evaluated the mechanical properties (microhardness and flexural strength) of 5 different 
composites after artificial aging (storage in distilled water or artificial saliva, or $2 \times 3,000$ thermal cycles) and stated that the solution used for the aging process and the frequency of cycles had no significant effect on the hardness or flexural strength of composite resins. ${ }^{26}$ Göhring et al. reported that water storage with/without thermocycling decreased the flexural strength of the Bellaglass ${ }^{\circledR}$, Sinfony ${ }^{\circledR}$ and Targis ${ }^{\circledR}$ composites, irrespective of their filler content or resin matrix composition. ${ }^{27}$

The destructive effects of water storage on the mechanical properties of composite resins occur for 2 reasons. First, water sorption increases the volume of the matrix and degrades its organic components due to the hydrolysis of silane bonds. The other reason is the solubility and release of some composite components into water, especially inactivated monomers. ${ }^{28}$ Fan et al. evaluated the mechanical properties of 4 types of composite resins following immersion in 3 different media. ${ }^{29}$ They showed that the hardness of composites with the Bis-GMA base, such as Filtek Z250, decreased after storage in distilled water, which is attributed to the potential of their resin matrix to soften in water. ${ }^{29}$ Crutis et al. suggested that a reduction in the hardness of nanocomposites in water may be related to the degradation of the resin matrix interface following greater water sorption due to the increased surface/volume ratio of nanofillers. ${ }^{30}$

A reduction in the hardness of the Vertise Flow selfadhesive composite following water aging may be related to the quality of its resin matrix, which has a high potential for water sorption. Vertise Flow contains glycero-phosphate dimethacrylate (GPDM) as its active monomer. This monomer contains an active acidic phosphate group and 2 active methacrylate groups. It has been reported that acidic resin monomers have greater water sorption than neutral resin monomers. ${ }^{31}$ Wei et al. concluded that Vertise Flow had greater hygroscopic expansion than UDMA with a polymer base, which is due to the presence of hydrophilic acid phosphate and spacer groups in GPDM. ${ }^{32}$

The filler type may also play a role in the water sorption of composite resins. It has been confirmed that composites containing barium and zinc glass fillers have a higher potential for hydrolytic degradation than those with silica and zirconia fillers. This may be due to the fact that some ions in the composition of these fillers are electropositive and have a greater tendency to react with water, which leads to the leaching of the fillers into water. Subsequently, the hydrogen ions of water penetrate into the spaces filled with barium and zinc and the increased accumulation of hydrogen ions leads to the failure of siloxane bonds and the silica network. ${ }^{33}$

A reduction in the hardness of the composites in this study might depend on the degree of conversion, which is an important factor that affects the hardness and modulus of elasticity of composite resins. The hardness of the resin matrix improves with an increased cross-linking between the polymer chains. In insufficiently polymerized resins, water molecules bond to unreacted monomers, causing a reduction in hardness. Thus, increasing the degree of conversion decreases the effect of water molecules on the mechanical properties of composite resins. ${ }^{34}$ The SEM micrographs from this study revealed changes in the composite surface, the separation of the filler particles, and the impaired smoothness as well as the erosion of the resin surface after aging in all 3 composite types, which explains a reduction in surface microhardness. These observations further confirmed the results of the Vickers hardness test.

Although surface microhardness is an influential mechanical property in the clinical service of composite restorations, some other physico-mechanical properties, such as flexural strength, wear resistance, the degree of conversion, and color stability, should also be taken into account when selecting a composite resin for tooth restoration, especially in high-stress-bearing areas. ${ }^{35}$

\section{Conclusions}

There were statistically significant differences in the surface microhardness of the composites before and after aging. All composites experienced a reduction in their surface microhardness after aging.

\section{ORCID iDs}

Sedighe Sadat Hashemikamangar (1)

https://orcid.org/0000-0002-7015-7527

Mohammad Zeynaddini Meymand (1)

https://orcid.org/0000-0002-0169-6439

Mohammad Javad Kharazifard (1) https://orcid.org/0000-0002-0613-884X

Sara Valizadeh (1) https://orcid.org/0000-0003-0383-7722

\section{References}

1. Negahdari K, Tavanagar MS, Bagheri R. Sorption, solubility, and surface microharness of 3 nanohybrid resin composites after 60 days of water storage. J Dent (Tehran). 2018;30(4):200-207.

2. Tekçe N, Pala K, Demirci M, Tuncer S. Changes in surface characteristics of two different resin composites after 1 year water storage: An SEM and AFM study. Scanning. 2016;38(6):694-700.

3. Baur V, llie N. Repair of dental resin-based composites. Clin Oral Investig. 2013;17(2):601-608.

4. Czasch $P$, llie N. In vitro comparison of mechanical properties and degree of cure of a self-adhesive and four novel flowable composites. J Adhes Dent. 2013;15(3):229-236.

5. Ghavam M, Soleimanpour M, Hashemikamangar SS, Ebrahimi $H$, Kharazifard MJ. Microshear bond strength of self-adhesive composite to ceramic after mechanical, chemical and laser surface treatments. Laser Ther. 2017;26(4):297-304.

6. Liebermann A, Wimmer T, Schmidlin PR, et al. Physicomechanical characterization of polyetheretherketone and current esthetic dental CAD/CAM polymers after aging in different storage media. J Prosthet Dent. 2016;115(3):321-328.e2.

7. Badra VV, Faraoni JJ, Ramos RP, Palma-Dibb RG. Influence of different beverages on the microhardness and surface roughness of resin composites. Oper Dent. 2005;30(2):213-219.

8. Moon JD, Seon EM, Son SA, Jung KH, Kwon YH, Park JK. Effect of immersion into solutions at various $\mathrm{pH}$ on the color stability of composite resins with different shades. Restor Dent Endod. 2015;40(4):270-276. 
9. Chladek G, Basa K, Żmudzki J, Malara P, Nowak AJ, Kasperski J. Influence of aging solutions on wear resistance and hardness of selected resin-based dental composites. Acta Bioeng Biomech. 2016;18(3):43-52.

10. Bala O, Arisu HD, Yikilgan I, Arslan S, Gullu A. Evaluation of surface roughness and hardness of different glass ionomer cements. Eur J Dent. 2012;6(1):79-86.

11. Heintze SD, Ilie N, Hickel R, Reis A, Loguercio A, Rousson V. Laboratory mechanical parameters of composite resins and their relation to fractures and wear in clinical trials - a systematic review. Dent Mater. 2017;33(3):e101-e114.

12. Pahlevan A, Tabatabaei MH, Arami S, Valizadeh S. Effect of LED and argon laser on degree of conversion and temperature rise of hybrid and low shrinkage composite resins. Open Dent. 2016;10:538-545.

13. Scougall-Vilchis RJ, Hotta $Y$, Hotta M, Idono T, Yamamoto K. Examination of composite resins with electron microscopy, microhardness tester and energy dispersive X-ray microanalyzer. Dent Mater J. 2009;28(1):102-112.

14. Braem M, Finger W, Van Doren VE, Lambrechts $P$, Vanherle G. Mechanical properties and filler fraction of dental composites. Dent Mater. 1989;5(5):346-348.

15. Sakaguchi RL, Ferracane J, Powers J. Craig's Restorative Dental Materials. $14^{\text {th }}$ ed. eBook. St Louis, MO: Mosby (Elsevier Health Sciences); 2018:6.

16. Blackham JT, Vandewalle KS, Lien W. Properties of hybrid resin composite systems containing prepolymerized filler particles. Oper Dent. 2009;34(6):697-702.

17. Tiba A, Charlton DG, Vandewalle KS, Ragain JC Jr. Comparison of two video-imaging instruments for measuring volumetric shrinkage of dental resin composites. J Dent. 2005;33(9):757-763.

18. Kundie F, Azhari $\mathrm{CH}$, Muchtar A, Ahmad ZA. Effects of filler size on the mechanical properties of polymer-filled dental composites: A review of recent developments. J Phys Sci. 2018;29(1):141-165.

19. Anfe TE, Caneppele TM, Agra CM, Vieira GF. Microhardness assessment of different commercial brands of resin composites with different degrees of translucence. Braz Oral Res. 2008;22(4):358-363.

20. Kwon $\mathrm{YH}$, Jeon GH, Jang CM, Seol HJ, Kim HI. Evaluation of polymerization of light-curing hybrid composite resins. J Biomed Mater Res B Appl Biomater. 2006;76(1):106-113.

21. Gajewski VES, Pfeifer CS, Fróes-Salgado NRG, Boaro LCC, Braga RR. Monomers used in resin composites: Degree of conversion, mechanical properties and water sorption/solubility. Braz Dent J. 2012;23(5):508-514.

22. David JR, Gomes OM, Gomes JC, Loguercio AD, Reis A. Effect of exposure time on curing efficiency of polymerizing units equipped with light-emitting diodes. J Oral Sci. 2007;49(1):19-24.

23. Hashemikamangar SS, Hasanitabatabaee M, Kalantari S, Gholampourdehaky M, Ranjbaromrani L, Ebrahimi $H$. Bond strength of fiber posts to composite core: Effect of surface treatment with $\mathrm{Er}, \mathrm{Cr}$ :YSGG laser and thermocycling. J Lasers Med Sci. 2018;9(1):36-42.

24. De Moraes RR, Marimon JLM, Schneider LF, Sinhoreti MAC, CorrerSobrinho L, Bueno M. Effects of 6 months of aging in water on hardness and surface roughness of two microhybrid dental composites. J Prostodont. 2008;17(4):323-326.

25. Yap AUJ, Wang X, Wu X, Chung SM. Comparative hardness and modulus of tooth-colored restoratives: A depth-sensing microindentation study. Biomaterials. 2004;25(11):2179-2185.

26. Hahnel S, Henrich A, Bürgers R, Handel G, Rosentritt M. Investigation of mechanical properties of modern dental composites after artificial aging for one year. Oper Dent. 2010;35(4):412-419.

27. Göhring TN, Gallo L, Lüthy H. Effect of water storage, thermocycling, the incorporation and site of placement of glass-fibers on the flexural strength of veneering composite. Dent Mater. 2005;21(8):761-772

28. Karimzadeh A, Ayatollahi MR, Shirazi HA. Mechanical properties of a dental nano-composite in moist media determined by nanoscale measurement. Int J Mater Mech Manuf. 2014;2(1):67-72.

29. Fan HY, Gan XQ, Liu Y, Zhu ZL, Yu HY. The nanomechanical and tribological properties of restorative dental composites after exposure in different types of media. J Nanomater. 2014;ID:759038.
30. Crutis AR, Shortall AC, Marquis PM, Palin WM. Water uptake and strength characteristics of a nanofilled resin-based composite. J Dent. 2008;36(3):186-193.

31. Hosaka K, Nakajima M, Takahashi M, et al. Relationship between mechanical properties of one-step self-etch adhesives and water sorption. Dent Mater. 2010;26(4):360-367.

32. Wei YJ, Silikas N, Zhang ZT, Watts DC. Hygroscopic dimensional changes of self-adhering and new-resin matrix composites during water sorption/desorption cycles. Dent Mater. 2011;27(3):259-266.

33. Alrobeigy NA. Mechanical properties of contemporary resin composites determined by nanoindentation. Tanta Dent J. 2017;14(3):129-137.

34. Okada K, Tosaki S, Hirota K, Hume WR. Surface hardness change of restorative filling materials stored in saliva. Dent Mater. 2001;17(1):34-39.

35. Knobloch L, Kerby RE, Clelland N, Lee J. Hardness and degree of conversion of posterior packable composites. Oper Dent. 2004;29(6):642-649. 
